\title{
Studies on Phagocytosis in Patients with Acute Bacterial Infections
}

H. Hank Simms, Michael M. Frank, Thomas C. Quinn, Steven Holland, and Thelma A. Gaither

Laboratory of Clinical Investigation, National Institute of Allergy and Infectious Diseases, National Institutes of Health, Bethesda, Maryland 20892

\begin{abstract}
Polymorphonuclear leukocytes (PMN) and monocytes from 20 patients with acute bacterial infections were examined for phagocytic function. PMN of patients expressed markedly enhanced phagocytosis as measured by the ingestion of erythrocyte (E)IgG and IgG/C3b-coated E. Phagocytosis of E coated with $\mathrm{C} 3 \mathrm{~b}$ alone was not seen, while low levels of ingestion of iC3b-E by patients' PMNs was noted. Monocytes from patients and controls expressed similar phagocytic activity in a fixed endpoint assay; however, the kinetics of phagocytosis by patients' monocytes was strikingly faster. Superoxide anion $\left(\mathrm{O}_{2}^{\circ}\right)$ and myeloperoxidase activities were similar to controls in PMN of four patients studied on day 1 of admission.

PMN from two of three patients studied longitudinally showed an initial elevation in EIgG phagocytosis, which fell to normal levels by day 4 , concomitantly with increased $\mathrm{O}_{2}^{\circ}$ generation and clinical improvement. Phagocytosis remained elevated in the third patient who did not clear his septicemia.

Surface membrane FcRII, FcRIII, CR1, and CR3 were similar on patient and control PMN. In contrast, FcRI was increased on PMN of five of seven patients by monomeric IgG binding, and on two of two patients by monoclonal anti-FcRI binding.

Thus, PMN and monocytes of patients with acute bacterial infections are either upregulated with regard to phagocytic function or are less susceptible to downregulation than are normal cells. This presumably would have a beneficial effect on host defenses during infection.
\end{abstract}

\section{Introduction}

Phagocytosis by PMN constitutes a critical mechanism of host defense against bacterial infection. Many in vitro studies have detailed changes in the state of activation and function of normal PMN in response to inflammatory and infectious stimuli $(1,2)$. What happens to PMN in patients with acute bacterial infections is less clear. Both increased $(3,4)$, normal and decreased $(5,6)$ phagocytic capabilities of PMN in patients with infection have been reported. In general, these studies used serum-opsonized particles as phagocytic targets. With the recognition that there exist multiple types of independently functioning, specific receptors for individual ligands on target par-

Address reprint requests to Dr. H. H. Simms, Rhode Island Hospital, Department of Surgery, 593 Eddy Street, Providence, RI 02903.

Received for publication 14 December 1987 and in revised form 8 August 1988.

J. Clin. Invest.

(C) The American Society for Clinical Investigation, Inc.

0021-9738/89/01/0252/09 $\$ 2.00$

Volume 83, January 1989, 252-260 ticles, it was of importance to reexamine this question using highly defined target particles.

This paper reports results of studies designed to assess the state of activation of PMN and monocytes with regard to phagocytosis in a receptor-specific fashion. The target particles consisted of sheep erythrocytes coated with known quantities of IgG (EIgG), ${ }^{1} \mathrm{C} 3 \mathrm{~b}$ (EAC3b), or iC3b (EAC3bi), or with known amounts of IgG plus C3b (EAC3b-IgG).

In a recent report, we showed that adherent PMN from normal, healthy individuals do not express a full phagocytic potential for EIgG when studied in media without scavengers of products of the oxidative burst (7). Phagocytic activity of PMN from normal individuals was markedly enhanced by sodium azide or catalase, which are inhibitors of various steps in the oxidative burst. This enhancement of phagocytosis by sodium azide was also shown with serum-opsonized Candida. PMN from chronic granulomatous disease (CGD) patients and from one patient with myeloperoxidase (MPO) deficiency showed markedly enhanced phagocytosis in comparison to normal PMN (7). These findings indicated that products of oxidative respiration regulate the phagocytic uptake of IgGsensitized targets in normal PMN and suggested that the degree of ingestion of targets is under physiologic control. It was of great interest to determine whether the phagocytic response of PMN from infected individuals was similar to that of normal controls. Moreover, we wished to determine whether the apparent normal downregulation of PMN during phagocytosis of IgG-sensitized targets was fully or partially reversed in PMN of infected patients. Studies in 20 infected patients and controls revealed markedly increased phagocytic capacity of patient PMN as evidenced by their enhanced ability to ingest EIgG and EAC3b-IgG in the absence of an inhibitor of the oxidative burst. This marked upregulation was not associated with alterations in the number of low affinity Fc receptors (FcRII or FcRIII), or of the important opsonic complement receptors, $\mathrm{CR} 1$ or $\mathrm{CR} 3$. Increased numbers of FcRI, however, were seen on the surface of PMN from five of seven infected patients studied.

In addition, longitudinal studies conducted on three patients with acute bacterial infection demonstrated marked upregulation of PMN phagocytosis concordant with the infectious process. In this study, we report an analysis of phagocytic capability as it relates to the kinetics of phagocytosis, MPO release, and superoxide anion production, and the expression of FcR (I, II and III), CR1, and CR3 in a series of individuals with documented severe bacterial infections.

1. Abbreviations used in this paper: CGD, chronic granulomatous disease; CR1, complement receptor 1; EAC3b-IgG, sheep erythrocytes opsonized with complement component C3; EDVBS, dextrose VBS; EIgG, erythrocyte coated with IgG; PBS-G, PBS with gelatin; PDBu, phorbol dibutyrate; PI, phagocytic index; VBS, veronal-buffered saline. 


\section{Methods}

Buffers and media. Veronal-buffered saline (VBS) low ionic-strength buffer containing $60 \%$ dextrose in VBS (DVBS), and VBS containing $10 \mathrm{mM}$ EDTA (EDTA-VBS) were prepared as previously described (8, 9). HBSS without $\mathrm{Ca}^{2+}$ and $\mathrm{Mg}^{2+}$ and RPMI 1640 containing L-glutamine were obtained from Gibco Laboratories, Grand Island, NY. PBS containing $1 \mathrm{mg} / \mathrm{ml}$ gelatin, $10 \mathrm{mM}$ EDTA and $0.05 \%$ sodium azide (PBS-G) was prepared as previously described (10). Hypotonic saline buffer containing $0.16 \mathrm{M}$ ammonium chloride, $3.7 \times 10^{-4} \mathrm{M}$ potassium bicarbonate, and $1.1 \times 10^{-4} \mathrm{M}$ EDTA was obtained from the NIH Media Unit.

Reagents. Reagents were obtained from the following sources: sodium azide and $30 \% \mathrm{H}_{2} \mathrm{O}_{2}$ from Fisher Scientific Co., Fair Lawn, NJ; Lymphocyte separation medium, Litton Bionetics, Kensington, MD; bovine serum albumin (fraction $\mathrm{v}$ ), 3,3' dimethoxybenzidine, phorbol dibutyrate $(\mathrm{PDBu})$, superoxide dismutase $(60,000 \mathrm{U} / \mathrm{ml})$ and cytochrome $c$ from Sigma Chemical Co., St. Louis, MO; Dextran T500 from Pharmacia Fine Chemicals, Uppsala, Sweden; and 2-ethylhexylphthalate and dibutyl phthalate were purchased from Eastman Kodak Co., Rochester, NY. Partially purified complement components, guinea pig $\mathrm{C} 1$ and human $\mathrm{C} 2$, were purchased from Diamedics, Miami, FL. Highly purified human C3 and C4 were prepared as described previously (11) as were Factors $H$ and $I$ (12).

Preparation of monomeric $I g G$. Monomeric $\mathrm{IgG}_{1}$ from plasma of patients with multiple myeloma was purified by sequential ammonium sulfate precipitation and DEAE-Sephacel ion-exchange chromatography (13). The resulting IgG was then loaded onto a $0.5-\mathrm{M}$ sieving column (Bio-gel A; Bio-Rad Laboratories, Richmond, CA) and the peak eluting as monomeric IgG was pooled and stored at $-70^{\circ} \mathrm{C}$. A portion of the monomeric IgG was then radiolabeled with ${ }^{125} \mathrm{I}$ to a specific activity of $1.72 \mu \mathrm{Ci} / \mu \mathrm{g}$ using the Iodobead iodination procedure (14). Aliquots of the radiolabeled preparation were applied to a $10-40 \%$ sucrose density gradient and centrifuged in an ultracentrifuge with an SW41 rotor (Beckman Instruments, Inc. Fullerton, CA) at $35,000 \mathrm{rpm}$ for $18.5 \mathrm{~h}$ at $4^{\circ} \mathrm{C}$. No contamination by oligomeric forms of IgG was observed. The radiolabeled monomeric IgG was stored at $4^{\circ} \mathrm{C}$ in the presence of $1 \% \mathrm{HSA}$ and $0.05 \%$ sodium azide. Immediately before each experiment, the monomeric IgG was centrifuged at $30 \mathrm{psi}$ for 30 min (Airfuge; Beckman Instruments) and the top half of the supernatant was used for study.

Monoclonal antibodies. 3G8, an MAb that recognizes the PMN low-affinity FcRIII was kindly provided by J. Unkeless (Mt. Sinai School of Medicine) and S. Clarkson (University of California, San Francisco) (15). 1B4, which recognizes CR1, was prepared as previously described (16). Fab fractions were prepared from both of these MAbs by published methods (17). IgG fractions of IV-3, a MAb that recognizes the PMN low affinity FCRII (18) and 32.2, which recognizes the PMN high affinity FcRI (19) were kindly provided by P. Guyre. The MAb, anti-Mol (mouse IgM), which binds to PMN CR3, was purchased from Coulter Immunology, Hialeah, FL.

MAbs were radiolabeled with ${ }^{125}$ I using the Iodobead iodination procedure (14). The specific activities of the MAbs were: 1B4:1.5 $\mu \mathrm{Ci} / \mu \mathrm{g}$, anti-Mol:0.27 $\mu \mathrm{Ci} / \mu \mathrm{g}, 3 \mathrm{G8:0.50} \mu \mathrm{Ci} / \mu \mathrm{g} ; \mathrm{IV}-31.10 \mu \mathrm{Ci} / \mu \mathrm{g}$; 32.2:0.35 $\mu \mathrm{Ci} / \mu \mathrm{g}$. The radiolabeled MAbs were stored at $4^{\circ} \mathrm{C}$ in the presence of $1 \% \mathrm{HSA}$ and $0.05 \%$ sodium azide. Immediately before each experiment, they were centrifuged at $30 \mathrm{psi}$ for $30 \mathrm{~min}$.

Cellular intermediates. The preparation of IgG and IgM fractions of rabbit anti-Forssman antibody and washed sheep erythrocytes (E) were as previously described (20). Varying dilutions of IgG antibody were added to $E$ at $1.5 \times 10^{8}$ cells $/ \mathrm{ml}$, followed by a 15 -min incubation at $30^{\circ} \mathrm{C}$ and three washes in VBS. The cells were resuspended to 1.5 $\times 10^{8} / \mathrm{ml}$ in DVBS for phagocytosis assays. Experiments using radiolabeled IgG antibody demonstrated that cells sensitized with a 1:2,000 dilution of this antibody have $\sim 18,000$ molecule IgG/cell. EAC3b were prepared as previously described by sequentially adding guinea pig $\mathrm{C} 1$, human $\mathrm{C4}$, human $\mathrm{C} 2$ and $\mathrm{C} 3$ to IgM-sensitized $\mathrm{E}$ (12). The number of $\mathrm{C} 3 \mathrm{~b}$ molecules bound per red blood cell (RBC) ranged from
$5 \times 10^{4}$ to $1 \times 10^{5}$. To these EAC $3 \mathrm{~b}$ cells, varying concentrations of IgG were added as described above. EAC3bi were prepared by incubating EAC3b in DVBS with $100 \mu \mathrm{g} / \mathrm{ml}$ of Factor $\mathrm{H}$ plus Factor I $(1: 25)$ for $45 \mathrm{~min}$ at $30^{\circ} \mathrm{C}$. The cells were washed twice and resuspended to $1.5 \times 10^{8} / \mathrm{ml}$ in DVBS. EAC3bi were shown in control experiments to express $\mathrm{C} 3$ in the form of $\mathrm{iC} 3 \mathrm{~b}$ and to be free of C3b (21).

Preparation of phagocytes. PMN were separated from venous blood samples by Ficoll-Hypaque density centrifugation and dextran sedimentation (22). The erythrocytes were removed by two hypotonic saline lysis steps. The PMN were washed two additional times and resuspended in RPMI to $5 \times 10^{5} / \mathrm{ml}$ for phagocytosis assays and to 20 $\times 10^{6} / \mathrm{ml}$ for MAb and monomeric IgG binding assays,

Monocytes were separated from venous blood using a colloidal silica-based continuous density gradient technique as described by the manufacturer (Sepracell-MN; Sepratech Corp., Oklahoma City, OK) (23). To assure purity, three Sepracell-Mn separation steps were used. By this method, $>90 \%$ of the isolated cells were monocytes by esterase staining and morphology. The Sepracell-Mn media was found to be free of endotoxin using a chromogenic substrate in the Limulus amebocyte lysate assay, in which the assay limit was $10 \mathrm{pg} / \mathrm{ml}$ (kit QCL-1000; M.A. Bioproducts, Walkersville, MD).

Study populations. Blood samples were obtained from patients with acute bacterial infections seen on the Infectious Disease Service at the Johns Hopkins Hospital. A patient profile is provided in Table I. Samples were drawn into heparinized tubes $(2 \mathrm{U} / \mathrm{ml})$ and immediately placed on ice at $0^{\circ} \mathrm{C}$ before transport to the NIH. Control subjects were laboratory personnel whose blood was drawn at the same time as that

Table I. Patient Profile

\begin{tabular}{|c|c|c|c|c|c|}
\hline & Patient & Diagnosis & WBC & $\begin{array}{c}\text { Febrile } \\
\left(\mathrm{T}>38^{\circ} \mathrm{C}\right)\end{array}$ & BC \\
\hline 1 & $28 \mathrm{y} / \mathrm{o}$ female & $\begin{array}{c}\text { Pneumococcal } \\
\text { pneumonia }\end{array}$ & $15.3 \mathrm{~K}$ & + & + \\
\hline 2 & 68 y/o male & $\begin{array}{c}\text { Pneumococcal } \\
\text { pneumonia }\end{array}$ & $16.4 \mathrm{~K}$ & + & - \\
\hline 3 & 40 y/o male & $\begin{array}{l}\text { S. aureus septic } \\
\text { arthritis }\end{array}$ & $27.3 \mathrm{~K}$ & + & + \\
\hline 4 & $69 \mathrm{y} / \mathrm{o}$ female & Acute mastoiditis & $13.3 \mathrm{~K}$ & + & - \\
\hline 5 & 24 y/o male & S. aureus endocarditis & $19.3 \mathrm{~K}$ & + & + \\
\hline 6 & 70 y/o male & $\begin{array}{l}E . \text { coli paracolostomy } \\
\text { abscess }\end{array}$ & $12.3 \mathrm{~K}$ & + & - \\
\hline 7 & $55 \mathrm{y} / \mathrm{o}$ female & S. aureus osteomyelitis & $25.3 \mathrm{~K}$ & + & + \\
\hline 8 & $75 \mathrm{y} / \mathrm{o}$ female & $\begin{array}{l}\text { H. influenzae } \\
\text { tracheobronchitis }\end{array}$ & $17.3 \mathrm{~K}$ & + & - \\
\hline 9 & $25 \mathrm{y} / \mathrm{o}$ female & $\mathrm{Gm}^{-}$septicemia & $24.3 \mathrm{~K}$ & + & + \\
\hline 10 & 40 y/o male & $\begin{array}{l}\text { Pneumococcal } \\
\text { pneumonia }\end{array}$ & $13.5 \mathrm{~K}$ & + & - \\
\hline 11 & $50 \mathrm{y} / \mathrm{o}$ male & S. aureus endocarditis & $35.0 \mathrm{~K}$ & + & + \\
\hline 12 & $40 \mathrm{y} / \mathrm{o}$ female & S. aureus septicemia & $16.5 \mathrm{~K}$ & + & + \\
\hline 13 & 79 y/o male & Klebsiella pneumonia & $24.0 \mathrm{~K}$ & + & - \\
\hline 14 & 84 y/o female & $\begin{array}{l}\text { E. coli } \\
\text { glomerulonephritis }\end{array}$ & $16.2 \mathrm{~K}$ & + & + \\
\hline 15 & $46 \mathrm{y} / \mathrm{o}$ female & $\begin{array}{r}\text { H. influenzae } \\
\text { pneumonia }\end{array}$ & $20.1 \mathrm{~K}$ & + & - \\
\hline 16 & $24 \mathrm{y} / \mathrm{o}$ female & S. aureus bacteremia & $12.3 \mathrm{~K}$ & + & + \\
\hline 17 & 27 y/o male & $\begin{array}{c}\text { Pneumococcal } \\
\text { pneumonia }\end{array}$ & $19.1 \mathrm{~K}$ & + & - \\
\hline 18 & $69 \mathrm{y} / \mathrm{o}$ male & E. coli bacteremia & $12.0 \mathrm{~K}$ & - & + \\
\hline 19 & 64 y/o male & $\begin{array}{l}\text { Pneumococcal } \\
\text { bacteremia }\end{array}$ & $17.3 \mathrm{~K}$ & + & + \\
\hline 20 & 54 y/o male & S. aureus cellulitis & $28.3 \mathrm{~K}$ & + & - \\
\hline
\end{tabular}


of the patients and immediately placed on ice at $0^{\circ} \mathrm{C}$ until usage. All specimens were used within $3 \mathrm{~h}$ of their being drawn.

Phagocytosis assays. $250 \mu \mathrm{l}$ of PMN at $5 \times 10^{5} / \mathrm{ml}$ were plated in each chamber of slide-mounted, eight-chamber tissue culture plates (Lab-Tec, Naperville, IL) and allowed to adhere for $45 \mathrm{~min}$ at $37^{\circ} \mathrm{C}$ in a $5 \% \mathrm{CO}_{2}$ incubator. $100 \mu \mathrm{l}$ of either E, EIgG, EAC3b-IgG, EAC3b, or EAC3bi was added to the adherent PMN and the plates were centrifuged at $50 \mathrm{~g}$ for $5 \mathrm{~min}$ at $4^{\circ} \mathrm{C}$. In kinetic assays, phagocytosis was stopped at $5,15,20,30$, and $40 \mathrm{~min}$ by bringing the chambers to $0^{\circ} \mathrm{C}$ and immediately adding $0^{\circ} \mathrm{C}$ lysing buffer to remove external RBC. After two exposures to lysing buffer, the cells were fixed with glutaraldehyde and stained with Giemsa. To assess the effects of sodium azide (an inhibitor of MPO) on phagocytosis, an aliquot of patient and control PMN at $5 \times 10^{5} / \mathrm{ml}$ was exposed to $10 \mathrm{mM}$ sodium azide for 15 min at $30^{\circ} \mathrm{C}$ before adherence in the culture plates. PMN that did not receive sodium azide had added buffer and were also incubated at $30^{\circ} \mathrm{C}$ for $15 \mathrm{~min}$. The percentage of PMN ingesting one or more red cells was determined microscopically (100X; oil immersion) and the total number of ingested red cells in $200 \mathrm{PMN}$ was recorded. The phagocytic index (PI) is expressed as the total number of ingested RBC per $100 \mathrm{PMN}$. In other assays phagocytosis was stopped after $30 \mathrm{~min}$ incubation at $37^{\circ} \mathrm{C}$, following the procedure described above.

Binding of ${ }^{125} I$-monomeric IgG and ${ }^{125} I-M A b s$. For ${ }^{125} \mathrm{I}$-monomeric IgG binding assays, PMN at $20 \times 10^{6} / \mathrm{ml}$ in PBS-G were incubated for 30 min at $37^{\circ} \mathrm{C}$, washed $\times 1$ with PBS-G to remove any free IgG, and resuspended to $20 \times 10^{6} / \mathrm{ml}$ in PBS-G. $100 \mu \mathrm{l}$ of cells was added to 12 $\times 75 \mathrm{~mm}$ polypropylene tubes, followed by the addition of ${ }^{125} \mathrm{I}$ monomeric IgG. In parallel, ${ }^{125} \mathrm{I}$ monomeric IgG was added in the presence of 50-100-fold excess of unlabeled monomeric IgG. The volume in each tube was equalized with PBS-G and the cells were incubated for $30 \mathrm{~min}$ at $37^{\circ} \mathrm{C}$. The cells were then pelleted by centrifuging through an oil mixture consisting of one part bis-2-(ethylhexyl) phthalate to three parts dibutyl phthalate. Bound monomeric IgG was determined from the level of radioactivity in the cell pellets and specific binding was calculated by subtracting ${ }^{125} \mathrm{I}-\mathrm{IgG}$ bound in the presence of 50-100-fold excess unlabeled IgG. In the ${ }^{125} \mathrm{I}$-MAb binding assays, 100 $\mu \mathrm{l}$ of PMN suspended in HBSS at $20 \times 10^{6} / \mathrm{ml}$ was incubated at $0^{\circ} \mathrm{C}$ for $1 \mathrm{~h}$ with ${ }^{125} \mathrm{I}-\mathrm{MAb}$. In control tubes ${ }^{125} \mathrm{I}-\mathrm{MAb}$ was added in the presence of 50-100-fold excess of unlabeled MAb. The remainder of the assay was as described for ${ }^{125} \mathrm{I}$-monomeric IgG binding.

Myeloperoxidase release. These assays were performed as previously described (24), using 96-well U-shaped Immulon 1 microtiter plates (Dynatech Laboratories, Chantilly, VA). PMN at $8 \times 10^{6} / \mathrm{ml}$ were pretreated with cytochalasin B $(5 \mu \mathrm{g} / \mathrm{ml})$ immediately before $25 \mu \mathrm{l}$ of the PMN was added to each well. The microtiter plates were then incubated for $30 \mathrm{~min}$ at $37^{\circ} \mathrm{C}$ in a $5 \% \mathrm{CO}_{2}$ incubator. $50 \mu \mathrm{l}$ of $0.2 \mathrm{M}$ sodium phosphate buffer, $\mathrm{pH} 6.2$, was then added followed by $25 \mu \mathrm{l}$ of a solution containing equal parts of $15 \mathrm{mM} \mathrm{H}_{2} \mathrm{O}_{2}$ combined with 3.9 mM 3'3' dimethoxybenzidine. A visible color reaction was stopped after $15 \mathrm{~min}$ at room temperature by $1 \%$ sodium azide. The optical density was assayed at 490 and $630 \mathrm{nM}$ on an MR580 model microelisa automatic reader (Dynatech Laboratories). Assays were carried out on resting PMN, PMN pretreated with $10 \mathrm{mM}$ sodium azide, and PMN plus $10 \mu 110 \%$ Triton X-100 to measure total MPO present.

Superoxide anion production. The amount of superoxide anion generated was assayed by measurement of the reduction of ferricytochrome $c$ (25). Assays were performed in 96-well flat bottom plates (Costar, Cambridge, MA). $100 \mu \mathrm{l}$ of cytochrome-c, with and without $\mathrm{PDBu}$ at $100 \mathrm{ng} / \mathrm{ml}$, was added to each chamber and $5 \mu \mathrm{l}$ of superoxide dismutase $(60,000 \mathrm{U} / \mathrm{ml})$ was added to control chambers. After the addition of $100 \mu \mathrm{l}$ of $\mathrm{PMN}$ at $5 \times 10^{5} / \mathrm{ml}$, the plate was incubated for $60 \mathrm{~min}$ at $37^{\circ} \mathrm{C}$ in a $5 \% \mathrm{CO}_{2}$ incubator. Optical density was assayed at $550 \mathrm{nM}$ on a dual beam microplate reader (model MR600; Dynatech Laboratories). Production of superoxide anion was determined using the molar extinction coefficient of cytochrome $c$ (6.3 with a light path of $3 \mathrm{~mm}$ ).

Statistical analysis. Phagocytosis and kinetic experiments were analyzed using two-way analysis of variance (ANOVA) unless otherwise stated. The binding of monomeric IgG, monoclonal antibodies, MPO release, and superoxide anion production were analyzed using the paired sample $t$ test. Values of $P<0.05$ were considered statistically significant.

\section{Results}

Phagocytosis in the absence of sodium azide. Phagocytosis assays were performed to determine if the PMN of acutely infected patients would ingest IgG-coated particles under conditions in which there was only minimal ingestion by control PMN (7). The results after $40 \mathrm{~min}$ of phagocytosis are shown in Fig. 1.

In the absence of sodium azide, the percentage of patient PMN ingesting EIgG at $1 / 2,000,1 / 4,000$, and $1 / 8,000$ dilutions of IgG were: $37.64 \pm 7.16 \%, 14.75 \pm 4.80 \%$, and $7.36 \pm 4.11 \%$, respectively. The percent phagocytosis by cells from normal controls in these experiments was $0-6 \%(n=14$ for patients, $n=12$ for controls; $P<0.002$ at $1 / 2,000 ; P<0.04$ at $1 / 4,000, P=\mathrm{NS}$ at $1 / 8,000$ comparing patients with controls using the Bonferroni inequality for multiple testing) (26). Patient phagocytosis of EAC3b-IgG at IgG dilutions of $1 / 4,000,1 / 8,000,1 / 16,000$ were: $54.00 \pm 5.90 \%, 33.50 \pm 4.13 \%$, and $16.30 \pm 2.13$, respectively. The percent phagocytosis of EAC3b-IgG by controls at the same dilutions of IgG were: $11.00 \pm 1.47 \%, 2.63 \pm 1.52 \%$, and $1.63 \pm 1.07 \%$, respectively ( $n$ $=5$ for patients; $n=5$ for controls; $P<0.002$ at each IgG dilution comparing patients with controls). Similarly, PI values also showed enhanced phagocytosis by patient PMN. Control values were 1-6 for ingesting EIgG and patient values were $90.77 \pm 24.20,36.08 \pm 15.31$, and $19.67 \pm 10.55$ for $1 / 2,000,1 / 4,000,1 / 8,000$ dilutions of $\mathrm{IgG}$, respectively $(P$ $<0.01$ at $1 / 2,000$ at each IgG concentrations comparing patients with controls). The PI values for EAC3b-IgG ingestion by patients' $P M N$ in the absence of sodium azide were: $142.00 \pm 22.93,82.90 \pm 15.79,40.10 \pm 7.47$ for $1 / 4,000,1 / 8,000$,

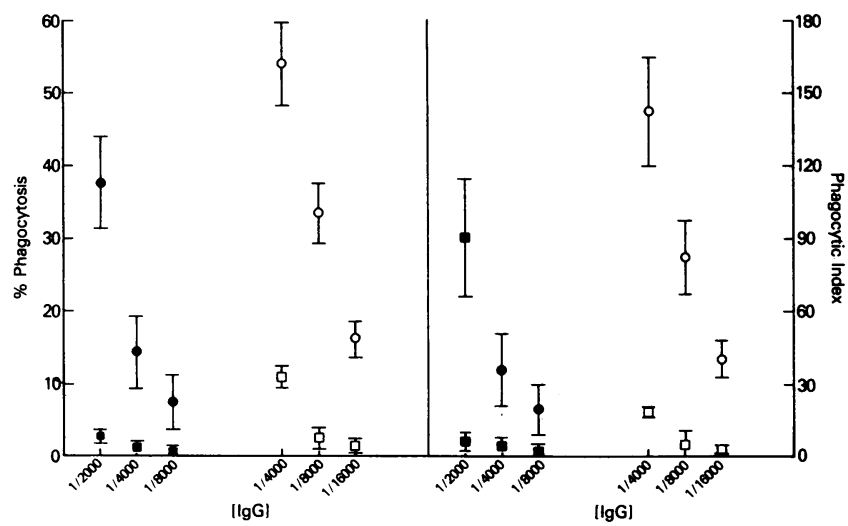

Figure 1. Phagocytosis of EIgG and EAC3b-IgG by patients and control PMN: PMN at $5 \times 10^{5} / \mathrm{ml}$ in RPMI were adhered in Lab-Tec chambers for $45 \mathrm{~min}$ at $37^{\circ} \mathrm{C} .100 \mu \mathrm{l}$ of target particles at $1.5 \times 10^{8}$ / $\mathrm{ml}$ was added to each chamber, and phagocytosis was assayed after $40 \mathrm{~min}$ at $37^{\circ} \mathrm{C}$. The percent phagocytosis is shown in the left panel; the PI values are on the right. EIgG and EAC 3b-IgG phagocytosis by patient PMN are represented by $\bullet$ and $\circ$ symbols, respectively; and for controls by $\square$ and $\square$, respectively. EIgG at $1 / 2,000$ dilution corresponded to $\sim 18,000 \mathrm{IgG} /$ cell; $1 / 16,000 \sim 2,000 \mathrm{IgG} /$ cell. Phagocytosis of EIgG and EAC3b-IgG was markedly enhanced in PMN from infected patients. 


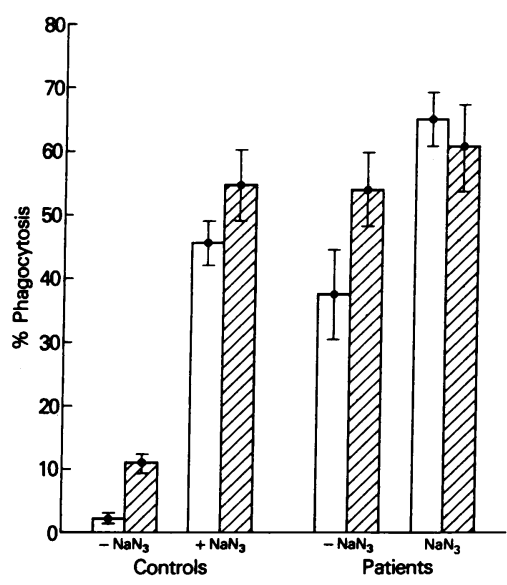

Figure 2. The effect of sodium azide on phagocytosis of EIgG and EAC 3b-IgG by patient and control PMN. The experiment was performed as in Fig. 1, except that PMN were pretreated with $10 \mathrm{mM}$ sodium azide for 15 min at $30^{\circ} \mathrm{C}$ before adherence in Lab-Tec chambers. EIgG and EAC3b-IgG phagocytosis is represented by open and hatched bars, respectively. Sodium azide consistently enhanced the percentage of patient and control PMN that ingested EIgG and EAC 3b-IgG. $E$ and $E A C 3 b$ were not ingested.

and $1 / 16,000$ dilutions of $\mathrm{IgG}$, respectively. In the control group, the PI values obtained for EAC3bIgG ingestion at identical $\mathrm{IgG}$ dilutions were: $18.36 \pm 2.60,4.50 \pm 6.23$, $2.75 \pm 1.70$, respectively $(P<0.01$ at each $\mathrm{IgG}$ concentration comparing patients with controls). Blood culture status did not accurately predict the extent of PMN upregulation with regard to phagocytosis.

Phagocytosis in the presence of sodium azide. One of the effects of sodium azide is to inactivate myeloperoxidase. Its effect on phagocytosis by PMN from controls and patients is shown in Fig. 2. The results shown represent phagocytosis of EIgG or EAC3b-IgG after $40 \mathrm{~min}$ incubation at $37^{\circ} \mathrm{C}$. With the addition of sodium azide, phagocytosis of EIgG by control PMN increased from $2.42 \pm 0.612 \%$ to $45.46 \pm 3.42 \%$, and that of EAC $3 \mathrm{~b}-\mathrm{IgG}$ increased from $11.00 \pm 1.47 \%$ to $54.88 \pm 5.31 \%$, $(P<0.001$ for EIgG and EAC3b-IgG phagocytosis using twosample $t$ test). Phagocytosis of EIgG by patient PMN increased from $37.64 \pm 7.18 \%$ to $65.07 \pm 4.32 \%$ and that of EAC $3 b-I g G$ increased from $54.00 \pm 5.90$ to $60.70 \pm 6.48 \%$ with the addition of sodium azide $(P<0.01$ for EIgG, $P=$ NS for EAC $3 \mathrm{~b}-\mathrm{IgG}$

phagocytosis using two-sample $t$ test). A similar enhancing effect of sodium azide was seen with all patient and control samples examined $(n=20)$.

The amount of phagocytosis by PMN from patients and controls correlated directly with the IgG concentration used to opsonize either E or EAC3b (Table II). The concentrations of IgG used to study PMN phagocytic activity ranged from $1 / 2,000$ to $1 / 16,000$ corresponding to $\sim 18,000$ and $2,250 \mathrm{IgG}$ molecules/RBC, respectively. Differences in phagocytosis at the varying IgG levels was significant $(P<0.001$ by two-way ANOVA for both PMN and monocytes from patients and controls). As expected, $\mathrm{C} 3 \mathrm{~b}$ enhanced the IgG-triggered ingestion of opsonized targets by PMN, primarily at lower concentrations of IgG. Notably, in the absence of IgG, E and EAC3b were not ingested by control or patient PMN and azide did not induce the ingestion of these target cells.

Phagocytosis by monocytes. Investigations were carried out to determine if PMN and monocytes behaved differently with regard to phagocytosis in patient and control subjects. Prior experiments showed that incubation of normal monocytes with sodium azide had no effect on phagocytosis by these cells (unpublished findings). In striking contrast to $\mathrm{PMN}$, phagocytosis of EIgG by patient and control monocytes was similar when overall phagocytic capacity was examined. As shown in Table II, the mean percent phagocytosis over time by monocytes of three patients studied was similar to that of the controls at each concentration of IgG used to opsonize the erythrocytes. PMN from these same patients expressed an upregulation in phagocytosis similar to that of other patients studied.

Phagocytosis of EAC3bi. CR3-mediated phagocytosis as assessed by the ingestion of EAC3bi was also assayed in the presence and absence of sodium azide (Table III). Approximately $9 \%$ of PMN from seven patients studied ingested EAC3bi in the absence of added azide, in comparison to $<1 \%$ of control PMN. This represented a significant difference in both the percentage of phagocytosis and the PI value. In the presence of azide, phagocytosis by patient and control PMN increased; however there was no significant difference between phagocytosis by patients and controls with azide present.

Kinetics of phagocytosis. The kinetics of phagocytosis was assayed by stopping phagocytosis at five time points (from 5 to $40 \mathrm{~min}$ ) as described in Methods. In Table IV, kinetics is expressed as the time necessary to achieve one-half the maximum amount of phagocytosis. IgG dilutions for PMN +10

Table II. Percent Phagocytosis by PMN and Monocytes from Patients and Controls

\begin{tabular}{|c|c|c|c|c|c|c|c|c|c|}
\hline & & Controls & & $n$ & & Patients & & $n$ & $P^{*}$ \\
\hline \multicolumn{10}{|c|}{$\mathrm{PMN}+10 \mathrm{mM} \mathrm{NaN}_{3}$} \\
\hline & $1 / 2,000^{*}$ & $1 / 4,000$ & $1 / 8,000$ & & $1 / 2,000$ & $1 / 4,000$ & $1 / 8,000$ & & \\
\hline \multirow[t]{2}{*}{ EIgG } & $44.8 \pm 4.3$ & $33.7 \pm 3.1$ & $18.4 \pm 2.6$ & 3 & $59.1 \pm 5.8$ & $46.8 \pm 4.0$ & $33.0 \pm 2.7$ & 3 & $<0.05$ \\
\hline & $1 / 4,000$ & $1 / 8,000$ & $1 / 16,000$ & & $1 / 4,000$ & $1 / 8,000$ & $1 / 16,000$ & & \\
\hline EAC3b-IgG & $57.1 \pm 4.3$ & $41.2 \pm 2.1$ & $26.8 \pm 2.0$ & 3 & $70.9 \pm 6.3$ & $59.0 \pm 5.5$ & $44.9 \pm 3.6$ & 3 & $<0.05$ \\
\hline \multicolumn{10}{|l|}{ Monocytes } \\
\hline & $1 / 20,000$ & $1 / 40,000$ & $1 / 80,000$ & & $1 / 20,000$ & $1 / 40,000$ & $1 / 80,000$ & & \\
\hline EIgG & $25.6 \pm 5.4$ & $18.8 \pm 4.1$ & $11.4 \pm 2.7$ & 3 & $23.9 \pm 4.8$ & $17.2 \pm 3.7$ & $11.3 \pm 2.5$ & 3 & NS \\
\hline
\end{tabular}

* IgG dilution of $1 / 2,000$ deposits $~ 18,000 \mathrm{IgG} /$ target cell. ${ }^{\ddagger}$ Phagocytosis by patient PMN was significantly greater than that of control PMN at each concentration of IgG used to prepare EIgG and EAC3b-IgG. PMN in the presence of $10 \mathrm{mM}$ sodium azide or monocytes without azide were preincubated in Lab-Tec chambers for $45 \mathrm{~min}$ at $37^{\circ} \mathrm{C}$ in $5 \% \mathrm{CO}_{2}$ incubator. Phagocytosis of EIgG, EAC3b-IgG was examined after $5,15,20,30$, and $40 \mathrm{~min}$ at $37^{\circ} \mathrm{C}$ and the mean percent phagocytosis over time was calculated. 
Table III. CR3-mediated Phagocytosis by Patient and Control PMN

\begin{tabular}{|c|c|c|c|c|}
\hline & \% phagocytosis & $\mathbf{N}$ & $\begin{array}{l}\text { Phagocytic } \\
\text { index }\end{array}$ & $\mathbf{N}$ \\
\hline \multicolumn{5}{|c|}{$\mathrm{PMN}-10 \mathrm{mM} \mathrm{NaN}_{3}$} \\
\hline Patient & 9.43 & 7 & 12.14 & 7 \\
\hline Control & 0.357 & 7 & 0.57 & 7 \\
\hline \multirow[t]{2}{*}{ Mean difference } & $9.07 \pm 2.13$ & & $11.57 \pm 2.56$ & \\
\hline & $P=<0.01$ & & $P<0.01$ & \\
\hline \multicolumn{5}{|c|}{$\mathrm{PMN}+10 \mathrm{mM} \mathrm{NaN}_{3}$} \\
\hline Patient & 16.93 & 7 & 22.93 & 7 \\
\hline Control & 5.79 & 7 & 6.43 & 7 \\
\hline \multirow[t]{2}{*}{ Mean difference } & $11.14 \pm 4.81$ & & $16.50 \pm 8.15$ & \\
\hline & $P=$ NS & & $P=$ NS & \\
\hline
\end{tabular}

$P$ values derived from paired sample $t$ test.

$\mathrm{mM} \mathrm{NaN}_{3}$ were $1 / 2,000,1 / 4,000$, and 1/8,000 for EIgG kinetics and were $1 / 4,000,1 / 8,000$, and $1 / 16,000$ for EAC3bIgG kinetics. IgG dilutions for monocyte kinetics were $1 / 20,000,1 / 40,000$, and $1 / 80,000$. Kinetics results represent data pooled over these various IgG dilutions. The rate of EIgG ingestion was significantly faster in monocytes from infected patients when compared with controls (12.9 vs. $27.4 \mathrm{~min}$, respectively, $P<0.01$ ). In contrast, the kinetics of ingestion of EIgG was similar when patient and cantrol PMN (both treated with $10 \mathrm{mM}$ azide) were compared (13.7 vs. $13.4 \mathrm{~min}$, respectively). Opsonization of $\mathrm{E}$ with $\mathrm{C} 3 \mathrm{~b}(50,000-100,000 / \mathrm{RBC})$ plus IgG significantly decreased the time of half maximal phagocytosis for both patient and control PMN (patient: 13.7 to $5.2 \mathrm{~min}$. with EIgG and EAC3b-IgG, respectively, $P<0.01$; control: 13.4 to $4.4 \mathrm{~min}$ for EIgG and EAC3b-IgG, respectively, $P<0.01$ ). There was no significant difference in the rate of ingestion of EAC3b-IgG by patient and control PMN. Finally, comparison of control monocytes and PMN revealed that significantly greater time is required to reach one-half

Table IV. Kinetics of Phagocytosis*

\begin{tabular}{lccc}
\hline & \multicolumn{3}{c}{$\begin{array}{c}\text { Mean amount of time (min) to reach } \\
\text { half-maximal phagocytosis }\end{array}$} \\
\cline { 2 - 4 } & Control & Patients & $P$ \\
\hline \multicolumn{4}{c}{ min } \\
PMN + 10 mM NaN & \multicolumn{3}{c}{} \\
EIgG & 13.4 & 13.7 & NS \\
EAC3b-IgG & 4.4 & 5.2 & NS \\
N & 3 & 3 & \\
$P^{\ddagger}$ & $<0.01$ & $<0.01$ & $<0.01^{\S}$ \\
Monocytes & & & \\
EIgG & 27.4 & 12.9 & \\
N & 3 & 3 &
\end{tabular}

* All kinetic assays were carried out to $\mathbf{4 0} \mathrm{min}$.

$\mathrm{N}$ Number of patients and controls tested.

¥P As expressed by two-way ANOVA comparing EAC3b-IgG ingestion vs. ElgG ingestion for both patient/control PMN

${ }^{8} P$ As expressed by two-way ANOVA comparing patient vs. control ingestion of EIgG. maximal phagocytosis for monocytes vs. PMN. For EIgG particles, control monocytes vs. PMN was 27.4 vs. $13.4 \mathrm{~min}(P$ $<0.01$ by two-way ANOVA). This is in contrast to phagocytosis by patient PMN and monocytes in which the kinetics of ingestion of EIgG is similar in the two types of phagocytic cells (12.9 vs. 13.7 for monocytes and PMN, respectively) (Table IV).

Longitudinal studies. From a subset of patients $(n=3)$, longitudinal studies were performed using PMN obtained from the patients over the course of one week. These assays were performed in a blinded fashion with the authors not aware of the clinical status of the patients during the course of the week. Blood samples for the assays were obtained on hospital days 1,4 , and 7 . The experiments performed were phagocytosis assays, binding of monoclonal anti-CR1, CR3, and FcR antibodies, MPO activity and superoxide anion production. These studies were designed to study the relationship between phagocytosis, expression of opsonic receptors and the oxidative burst in patients and controls and to determine if the heightened phagocytic activity of patient PMN normalized as patients improved clinically.

Data from the first two patients studied were pooled; the third patient studied in a blind fashion was quite different from those described above. This patient had severe bacterial endocarditis with a degree of leukocytosis not found in the other patients and $42 \%$ bands. More importantly, he did not clear his septicemia during the period of study. This patient's PMN phagocytosis was abnormal at all time points although the initial increase was minimal. Unlike the other patients, this individual showed a progressive increase in the extent of phagocytosis of test particles concordant with his inability to clear his septicemia.

Fig. 3 shows the mean percent phagocytosis and mean phagocytic index (PI) in the absence of azide treatment for the two patients who cleared their infection and for paired normal controls over time. Control PMN values during the week were $0-2 \%$ and 5-10 for percent phagocytosis and PI, respectively. The percentage of PMN from patients ingesting EIgG was markedly greater than that of controls on day 1 ; however this activity dramatically decreased over time, falling from an average of $53 \%$ phagocytosis on day 1 to $7 \%$ by day 7 . The PI values fell from an average of 195.5 on day 1 to 10.5 on day 7 ( $P<0.01$ by the Bartholomew test for percent phagocytosis and phagocytic index when comparing mean differences between patients and controls) (27). The decrease in phagocytic activity by both patients' PMN, correlates with their improved clinical condition (lower temperature decreased WBC count and clearance of bacteremic state).

$M P O$ release and superoxide anion generation. MPO release and superoxide anion generation were measured on each of $3 \mathrm{~d}$ of the longitudinal study. MPO was measured in resting PMN, PMN treated with sodium azide and in cells treated with $10 \%$ Triton $\mathrm{X}-100$. Table $\mathrm{V}$ shows that no significant differences were found between resting patient and control PMN nor were significant differences found in total myeloperoxidase activity as assessed using $P M N$ incubated with Triton $\mathrm{X}-100$.

Table $\mathrm{V}$ also shows that resting PMN from patients and controls did not exhibit significant differences in superoxide generation on day 1 , day 4 , or day 7 . Patient PMN consistently exhibited less superoxide anion release with PDBu stimulation than did controls, although this difference just failed to reach 


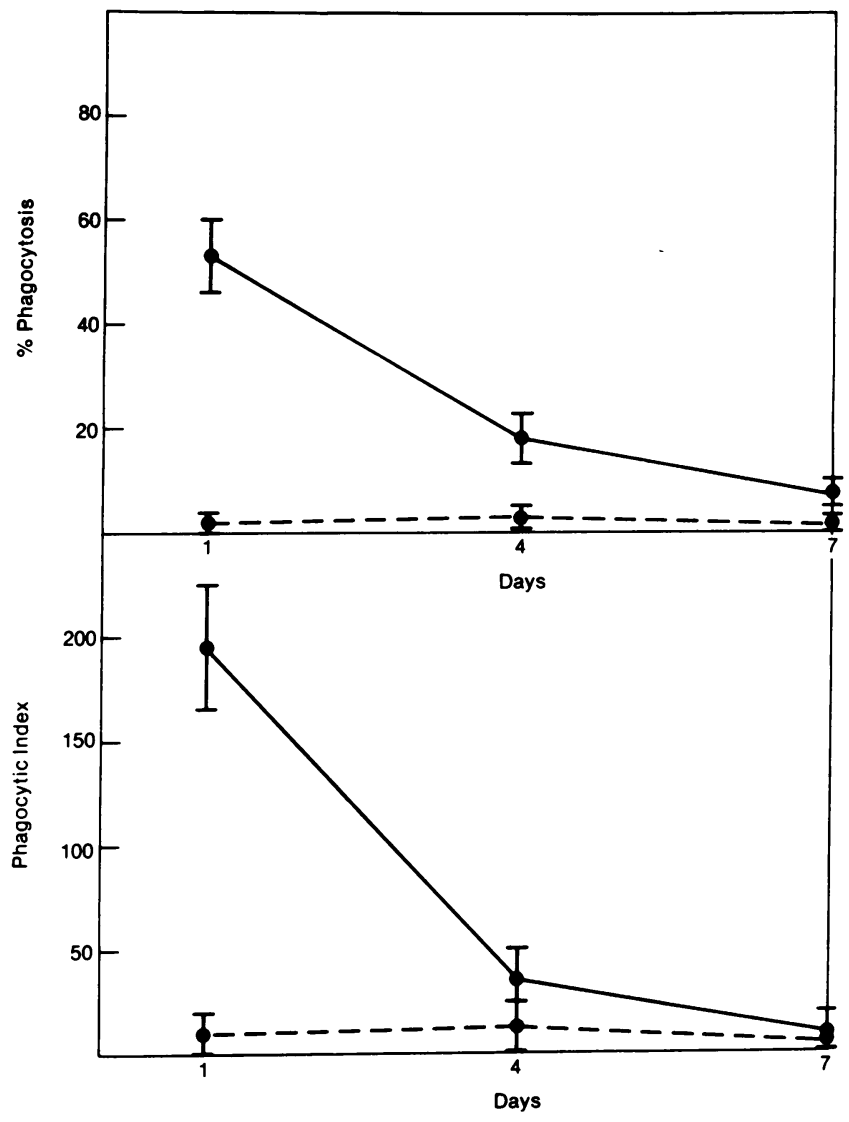

Figure 3. Phagocytosis of EIgG by patient and control PMN over time. These studies were done in the absence of added azide. Results represent the average of percent phagocytosis and PI of two patients and two controls studied on three different days. Days 1, 4, 7 represent days of hospitalization. Phagocytosis assays were carried out as described in Methods using EIgG bearing 18,000 IgG/cell. EIgG phagocytosis by patient and control PMN is represented by solid and hatched lines, respectively.

statistical significance. There was, however, a significant increase in patient superoxide anion production between days 1 and 4, concordant with a dramatic decrease in phagocytosis $(P$ $<0.02$ by two sample $t$ test).

Table VI represents a summary of experiments in which the data from patients studied on day 1 in the longitudinal study (Table V) was combined with superoxide anion and myeloperoxidase activity obtained from two additional patients studied on day 1 of admission and their controls. MPO activity was similar for the four patients and controls, and superoxide production by nonstimulated PMN from patients and controls was also similar. Interestingly, superoxide production was consistently lower in PdBu-stimulated patient PMN; however the difference just failed to reach statistical significance.

${ }^{125}$ I monomeric IgG and ${ }^{125}$ I monoclonal antibody binding. To assess the expression of the FcRIII, CR1 and CR3 on patient and control PMN, the binding of ${ }^{125} \mathrm{I}-\mathrm{MAbs}$ and ${ }^{125} \mathrm{I}$ monomeric IgG was examined. There were no significant differences between patient and control binding of 3G8, 1B4, or anti-Mo-1 (Table VII), nor was there a difference in receptor expression over time in the patients during the course of the longitudinal study.
In a second group of patients studied within $36 \mathrm{~h}$ of hospital admission, the number of FcRI and FcRII present on the surface of patient PMN was determined. The number of highaffinity FcR 1 was assayed using both ${ }^{125} \mathrm{I}$ monomeric IgG and radiolabeled MAb 32.2. Table VII represents data from both the longitudinal study examining 3G8, 1B4 and anti-Mol binding along with data derived from the second group of patients studied (IV-3, 32.2, and monomeric IgG binding). No increase in the number of low-affinity FcRII was seen but five out of seven patients' PMN expressed the high-affinity Fc receptor as measured by monomeric IgG binding while two of these five patients tested for 32.2 binding were both positive.

\section{Discussion}

The critical importance of phagocytic cells in host defense has been known for a century. It is also well known that phagocytic cells can undergo activation with alterations in function of many cellular systems. Recently, various cytokines and inflammatory factors have been shown to affect the activation process. These cytokines both upregulate and downregulate many cellular processes. It is known that infection is associated with the release of many of these factors, and it is reasonable to expect that these factors are of importance in determining the host response to infectious agents. For this reason, it is perhaps surprising that there are relatively few studies of phagocytosis by neutrophils and monocytes from patients with infection. In previous studies both upregulation and downregulation of the phagocytic process have been reported during infection (3-6). In general, these studies have used serum opsonized targets. It is now known that such targets have a number of different opsonins on their surface, each of which interact with different membrane receptors. These various receptors behave differently in biologic systems, in part explaining the lack of uniformity of the reported data. It was, therefore, of interest to reexamine the phagocytic capacity of a selected group of patients during infection using well defined target particles that would allow for an assessment of specific receptor functions. Sheep erythrocytes, sensitized with known amounts of IgG antibody, known amounts of highly purified human $\mathrm{C} 3 \mathrm{~b}$ plus $\mathrm{IgG}$, or with $\mathrm{C} 3 \mathrm{~b}$ or $\mathrm{iC} 3 \mathrm{~b}$ alone, were used as target particles in the studies reported here.

Using similar target particles, Gaither et al. recently reported that products of the oxidative burst of phagocytic cells, formed during phagocytosis of IgG sensitized targets, rapidly downregulate the normal phagocytic process (7). Patients with chronic granulomatous disease and MPO deficiency, who fail to have a normal oxidative burst, have a marked upregulation in phagocytosis (7). Stendahl and co-workers made similar observations with MPO deficient PMN and also concluded that products of the oxidative burst reduce phagocytosis (28). It has also been shown that platelet-derived growth factor, which downregulates the normal oxidative burst, also upregulates phagocytosis (29). It was therefore possible that products of the oxidative burst, formed during phagocytosis of bacteria, might downregulate phagocytic function in infected individuals.

In this report, we compared phagocytosis by PMN and monocytes of patients with acute bacterial infections with that of normal individuals. We confirmed our previous finding that phagocytosis by normal PMN in the absence of oxygen radical scavengers is greatly enhanced when the formation of toxic 
Table $V$.

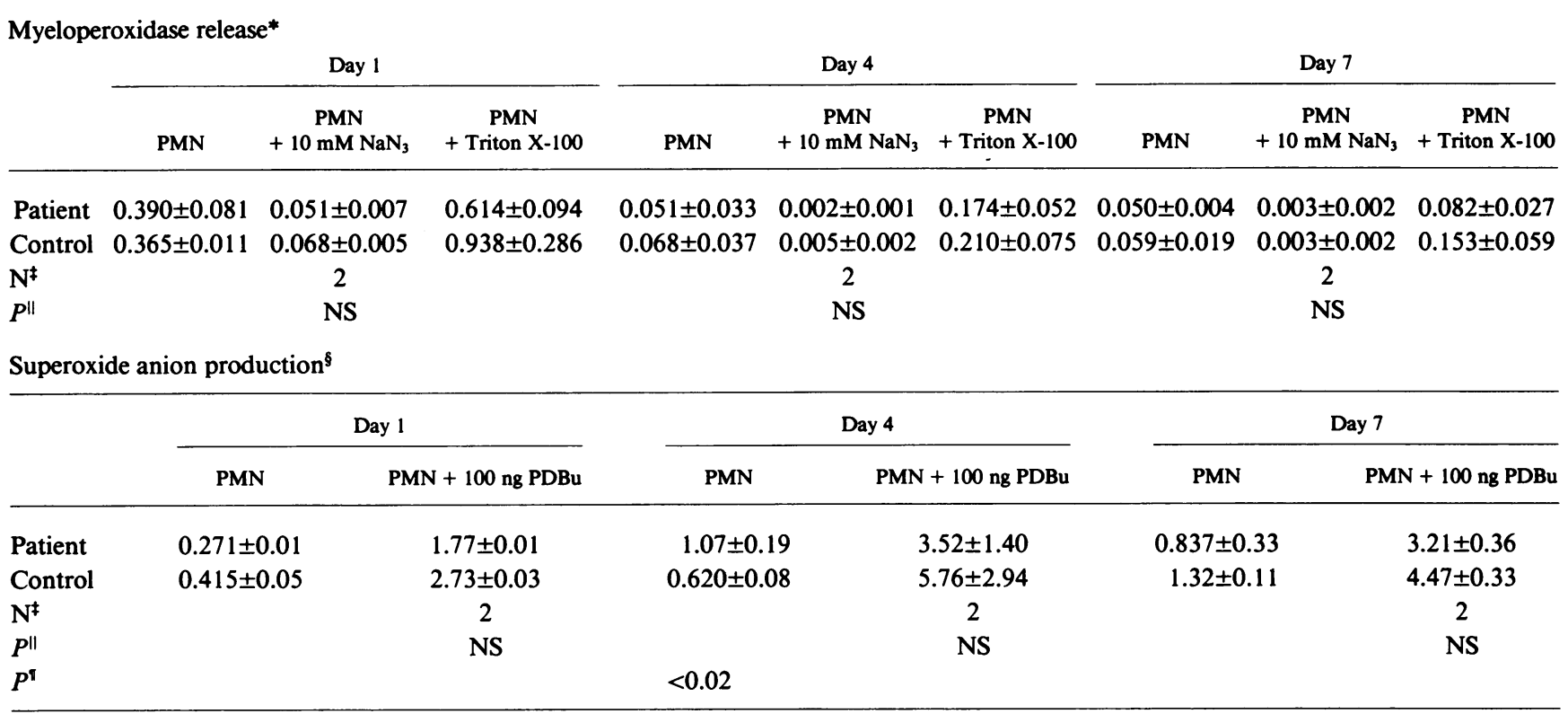

* MPO results expressed are average ODs of assays performed in triplicate. ${ }^{\ddagger}$ Two of the four patients studied above (Table VI) were studied longitudinally on days 4 and 7 of their hospital course. ${ }^{8}$ SOP results expressed are nM superoxide anion/5 $\times 10^{5} \mathrm{PMN} / \mathrm{h}$. " Comparison of patients and controls by paired-sample analysis. 'As measured by two sample $t$ test; comparing increase in patient unstimulated PMN superoxide production between days 1 and 4 vs. the change in controls.

oxidative products of the MPO- $\mathrm{H}_{2} \mathrm{O}_{2}$-halide system is blocked, i.e., by incubation with sodium azide, a potent inhibitor of MPO. In the absence of such treatment, normal PMN expressed minimal phagocytic activity and did not phagocytize targets heavily coated with IgG antibodies. It is important to emphasize that these differences in the extent of phagocytosis do not represent differences in the rate of breakdown of the target erythrocytes. In our previous report (7), sodium azide was found to increase phagocytosis of serum-opsonized Candida, a relatively nondegradable particle, as well as EIgG. In contrast to the findings in normals, PMN from patients with acute bacterial infection showed substantial phagocytosis of

Table VI.

\begin{tabular}{|c|c|c|c|c|}
\hline \multicolumn{5}{|c|}{ Myeloperoxidase release* Day 1} \\
\hline & PMN & $\mathrm{PMN}+10 \mathrm{mM} \mathrm{NaN}_{3}$ & PMN + Triton X-100 & $\mathbf{N}^{\ddagger}$ \\
\hline Patient & 0.256 & 0.069 & 0.658 & 4 \\
\hline Control & 0.230 & 0.047 & 0.664 & 4 \\
\hline Mean difference & $0.026 \pm 0.024$ & $0.022 \pm 0.015$ & $-0.006 \pm 0.1 \times 8$ & \\
\hline$P$ & NS & NS & NS & \\
\hline
\end{tabular}

Superoxide anion production ${ }^{8}$ Day 1

\begin{tabular}{lccr} 
& PMN & PMN + 100 ng PDBu & $\mathrm{N}^{\ddagger}$ \\
\hline Patient & 0.383 & 3.06 & 4 \\
Control & 0.405 & 4.11 & 4 \\
Mean difference & $+0.022 \pm 0.074$ & $+1.04 \pm 0.039$ & \\
$P^{\prime \prime}$ & $\mathrm{NS}$ & 0.076 & \\
\hline
\end{tabular}

* MPO results expressed are average ODs of assays performed in triplicate.

* Four different patients/controls studied in four separate days.

SOP results expressed are $\mathrm{nM}$ superoxide anion $/ 5 \times 10^{5} \mathrm{PMN} / \mathrm{h}$

"Comparison of patients and controls by paired-sample analysis. both EIgG and EAC3b-IgG targets in the absence of an inhibitor of the oxidative burst (Fig. 1). Phenotypically, these cells are markedly upregulated above the level of activity seen in normal individuals. Interestingly, in longitudinal studies of two patients, the apparent upregulation of PMN phagocytosis was temporally related to their illness. The ability to ingest EIgG particles in the absence of sodium azide diminished over time and corresponded with the patients' clinical improvement (Fig. 3). In a third patient, clinically extremely ill with endocarditis and staphylococcal septicemia, phagocytosis by neutrophils in the absence of azide increased progressively over the $10 \mathrm{~d}$ of study as the patient remained bacteremic, febrile, and clinically ill. When the extent of phagocytosis by control and patient PMN was examined in the presence of 10 $\mathrm{mM}$ azide, ingestion of EIgG and EAC3b-IgG was also found to be consistently greater with patient PMN (Table II; Fig. 2).

We also studied phagocytosis of $\mathrm{C} 3 \mathrm{~b}$ - and iC $3 \mathrm{~b}$-coated targets. As in normal PMN, PMN from patients did not phagocytose $\mathrm{C} 3 \mathrm{~b}$ coated particles, even with as many as $100,000 \mathrm{C} 3 \mathrm{~b} /$ target. Interestingly, although there was no phagocytosis of iC $3 b$-coated targets by normal PMN, 5 of 7 patients showed phagocytosis of $\mathrm{iC} 3 \mathrm{~b}$-coated targets, although the extent of phagocytosis was low (Table III).

In marked contrast to PMN, monocytes from infected patients did not demonstrate upregulation of the extent of phagocytosis when compared with controls (Table II), and azide was not found to enhance phagocytosis of control or patient monocytes (data not shown). Interestingly, analysis of the kinetics of phagocytosis revealed striking differences in the rate of ingestion by patient and control monocytes, but not PMN. Furthermore, patient monocytes ingested EIgG particles markedly faster than did control monocytes, whereas the rate of ingestion by patient and control PMN was similar (Table IV). Thus, 
Table VII. Molecules/Cell of ${ }^{125} I$ MAbs and ${ }^{125}$ I Monomeric IgG Bound to PMN

\begin{tabular}{lcccccc}
\hline & $3 G 8$ & IV-3* & $32.2^{*}$ & Monomeric IgG & IB4 & Anti-Mo-1 \\
\hline Patients & $1.30 \times 10^{5}$ & $5.12 \times 10^{4}$ & $3.30 \times 10^{3}$ & $2.14 \times 10^{3}$ & $2.74 \times 10^{4}$ & $2.93 \times 10.4$ \\
Controls & $1.20 \times 10^{5}$ & $2.77 \times 10^{4}$ & $0.428 \times 10^{3}$ & $0.651 \times 10^{3}$ & $3.04 \times 10^{4}$ & $2.83 \times 10.4$ \\
$\mathrm{~N}$ & & 2 & 2 & 7 & 6 & 3 \\
$\mathrm{~N}^{\ddagger}$ & 6 & & & $1.49 \pm 587$ & \pm 0.30 & \pm 0.10 \\
Mean & \pm 0.10 & $2.35 \pm 2.29$ & $2.88 \pm 90$ & $\times\left(10^{3}\right)$ & $\times 10^{5}$ & NS \\
$\quad$ difference & $\times\left(10^{5}\right)$ & $\times\left(10^{4}\right)$ & $\times\left(10^{3}\right)$ & $P<0.05$ & NS \\
$P^{\S}$ & $\mathrm{NS}$ & $\mathrm{NS}$ & $P<0.02$ & & NS \\
\hline
\end{tabular}

* Quantities of MAb used do not represent saturating amounts of ligand. N, Number of times assay performed on patient/control PMN.

₹ $3 \mathrm{G} 8$ and 1B4 binding represent two separate patients studied on three different days in the longitudinal study while anti-Mo-1 binding represents one patient studied on three different days. ${ }^{\S}$ As measured by paired sample analysis.

the rate of ingestion by monocytes appears to be upregulated in infected patients, although the total phagocytic capacity is similar to that of controls. When normal phagocytes were compared, a significant lag in ingestion of EIgG by control monocytes was observed, in comparison to PMN. This difference in phagocytic rate was overcome in infected monocytes. The rate of RBC ingestion by PMN for both patients and controls was significantly faster with EAC3b-IgG targets (CR 1 and $\mathrm{FCR}$ ) as opposed to EIgG targets. Thus, ligation of two receptors greatly enhances the rate and the extent of ingestion. Together, these data indicate that monocytes, as well as PMN, are capable of upregulation in infected individuals. Upregulation is strikingly different with these two cell types. In the case of PMN, the extent of phagocytosis is profoundly upregulated, and targets that are not phagocytosed at all by normal PMN are ingested by cells from infected patients. In contrast, the extent of monocyte phagocytosis is not markedly altered, but the kinetics are quite different.

Along with studies of phagocytosis we examined superoxide anion production and MPO release from patient and control PMN. In contradistinction to patients with CGD that we studied previously (7), patients with acute bacterial infection have normal mechanisms for generating superoxide and MPO in the resting state (30-32). Solomkin et al. reported normal superoxide formation in patients with intraabdominal infections in response to FMLP but not with serum opsonized zymosan (25). We found that overall superoxide anion production was similar in resting patient and control PMN. Superoxide anion generation was increased over baseline in both patient and control PMN upon stimulation with PDBu; and there was no significant difference $(P<0.076)$ in stimulated PMN from patients and controls (Table VI). It is important to note that in the two patients studied longitudinally there was reduced superoxide production in both resting and stimulated PMN on day 1, during which time, phagocytosis was maximal for both patients (Fig. 3). While superoxide levels in infected PMN were initially reduced, they reached supra normal values by the end of the fourth hospital day (Table V); and phagocytosis fell significantly by the fourth hospital day. On day 7 , superoxide levels in patient PMN was similar to that of day 4, and phagocytic activity was minimal. It should be noted that, there was no significant difference by statistical analysis between patient and control PMN production of superoxide on days 1,4 , or 7 . However, the increase in superoxide production by patient PMN from day 1 to day 4 was highly significant when compared to the increase seen in control PMN. It is possible that this diminished superoxide production by patient PMN early in the course of infection (day 1) may play a role in allowing upregulation of PMN phagocytosis during the most acute phase of bacterial infection. In contrast to superoxide anion generation, we found no significant differences in MPO release by patient and control PMN, nor was there a difference in total MPO as assessed in Triton X-100 treated PMN. Bass et al. (33) reported that a subpopulation of primed PMN is responsible for much of the increased $\mathrm{H}_{2} \mathrm{O}_{2}$ production seen in patients with acute bacterial and Candida infections. It is possible that in the patients studied here a subpopulation responsible for superoxide anion production may increase during the early phase of acute infection as the patients clinical condition improves.

It was of importance to test for differences in receptor expression as a possible factor in patient PMN upregulation. The binding of radiolabeled monoclonal antibodies to three major opsonic receptors was followed in the longitudinal studies: 3G8, 1B4, and anti-Mo-1; MAb against PMN FcRIII, and CR1, and CR3, respectively. There was no significant difference in 3G8, 1B4, or anti-Mo-1 binding on any day that they were tested. In addition, utilizing radiolabeled monomeric IgG and radiolabeled MAbs, we assayed the surface expression of PMN FcRI and FcRII in a series of patients studied within 36 $h$ of hospital admission. No increases in FcRII were seen, but a striking increase in the number of FcRI was seen both by binding of ${ }^{125}$ I monomeric IgG and ${ }^{125} \mathrm{I} 32.2$, a MAb directed against the PMN high-affinity receptor (Table VII). The increase in ${ }^{125}$ I monomeric IgG binding was seen on $5 / 7$ patients tested. In $2 / 2$ patients tested, anti-FcRI binding was increased. The role of the high-affinity $\mathrm{Fc}$ receptor in the upregulation of the patient PMN is not yet known.

In summary, PMN and monocytes from patients with acute bacterial infection are upregulated with respect to $\mathrm{Fc}$ receptor-mediated phagocytosis. The total phagocytic capacity of PMN is enhanced, whereas the rate of ingestion is enhanced in monocytes of infected patients. This effect does not appear to be due to differences in the number of opsonic receptors (FcRII, FcRIII, CR1, or CR3) on PMN; however the number of FCRI is strikingly increased. A low level of CR3-mediated ingestion was observed in infected PMN but these cells were not activated to phagocytize via CR1. MPO release and total MPO content were similar in patient and control PMN. Superoxide anion generation by unstimulated patient PMN was low at a time that phagocytosis was markedly greater than that of normal PMN; it rose to levels over controls as phagocytosis 
decreased toward the normal range. Thus the response to infection in humans is associated with alterations in PMN phagocytic and oxidative functions. Presumably this marked upregulation in phagocytic function represents a complex physiologic response that serves to provide an important additional measure of host defense.

\section{Acknowledgments}

The authors are grateful to Donna Martin for manuscript preparation and editing. We also thank Dr. David Alling for assistance in statistical analysis.

\section{References}

1. Smith, C. W., C. Hollus, R. A. Patrick, and C. Hossett. 1979. Mobility and adhesiveness in human neutrophils. Effects of chemotactic factors. J. Clin. Invest. 63:221-229.

2. Zimmerli, W., B. Seligmann, and J. I. Gallin. 1986. Exudation primes human and guinea pig neutrophils for subsequent responsiveness to the chemotactic peptide $\mathrm{N}$ formyl methionyl leucyl phenylalanine and increases complement C3bi receptor expression. J. Clin. Invest. 77:925-933.

3. Barbous, A. G., C. D. Alfred, C. O. Solberg, and H. R. Hill. 1980. Chemiluminescence by PMNs from patients with active bacterial infections. J. Infect. Dis. 141:14-26.

4. Krukowski, Z. H., and G. Smith. 1983. A unifying concept of PMN function in acute bacterial infections. World J. Surg. 7(3):424429.

5. Solberg, C. O., and K. B. Hellum. 1972. Neutrophil granulocyte function in bacterial infections. Lancet. ii:727-730.

6. Van Dijk, W. C., H. S. Verbrugh, M. E. Van der Tol, R. Peters, P. K. Peterson, P. G. Quie, and J. Verhoef. 1980. Interactions of phagocytic and bacterial cells in patients with bacteremia caused by gram-negative rods. J. Infect. Dis. 141:441-449.

7. Gaither, T. A., S. R. Medley, J. I. Gallin, and M. M. Frank. 1987. Studies of phagocytosis in chronic granulomatous disease. Inflammation. 11(2):211-227.

8. Mayer, M. M. 1961. Complement and complement fixation. In Experimental Immunochemistry. E. A. Kabat, editor. Charles C Thomas, Springfield, IL. 151-209.

9. Rapp, H. J., and T. Borsos. 1970. Molecular basis of complement actions. Appleton-Century-Croft, New York. 75-134.

10. Fries, L. F., R. P. Hall, T. S. Lawley, G. A. Crabtree, and M. M. Frank. 1982. Monocyte receptors for the Fc portion of IgG studied with monomeric human IgG1: normal in vitro expression of $\mathrm{Fc} \gamma$ receptors in HLA-B8/DRW ${ }_{3}$ subjects with defective $\mathrm{Fc} \gamma$-mediated in vivo clearance. J. Immunol. 129:1041-1049.

11. Hammer, C. H., G. H. Wertz, L. Renfer, H. Gresham, and B. F. Tack. 1981. Large scale isolation of functionally active components of the human complement system. J. Biol. Chem. 256:3995-4006.

12. Gaither, T. A., C. H. Hammer, J. E. Gadek, K. Katusha, M. Santaella, and M. M. Frank. 1983. Cleavage of membrane-bound C3b and C3bi by viable human neutrophils (PMN). Mol. Immunol. 20:623-635.

13. Williams, C. A. 1967. Methods in Immunology and Immunochemistry. Academic Press, New York. 323-325.

14. Markwell, M. A. K. 1982. A new method of protein iodination. Anal. Biochem. 125:427-432.
15. Fleit, H. B., S. D. Wright, and J. C. Unkeless. 1982. Human neutrophil $\mathrm{Fc} \gamma$ receptor distribution and structure. Proc. Natl. Acad. Sci. USA. 79:3275-3279.

16. O'Shea, J. J., E. J. Brown, B. E. Seligmann, J. A. Metcalfe, M. M. Frank, and J. I. Gallin. 1985. Evidence for distinct intracellular pools of receptors for $\mathrm{C} 3 \mathrm{~b}$ and $\mathrm{C} 3 \mathrm{bi}$ in neutrophils. J. Immunol. 134:2580-2587.

17. Porter, R. R. 1959. The hydrolysis of rabbit $\gamma$-globulin and antibodies with crystalline papain. Biochem. J. 73:119-126.

18. Looney, R. J., D. N. Ryan, K. Takahashi, H. B. Fleit, H. J. Cohen, G. N. Abraham, and C. L. Anderson. 1986. Identification of a second class of IgG Fc receptors on human neutrophils. J. Exp. Med. 163:826-836.

19. Sher, L., P. M. Guyre, C. G. Anderson, and M. W. Fanger. 1986. Heteroantibody-mediated cytotoxicity: antibody to the high affinity Fc receptor for IgG mediates cytotoxicity by human monocytes that is enhanced by interferon- $\gamma$ and is not marked by human IgG1. $J$. Immunol. 137:3378-3386.

20. Frank, M. M., and T. A. Gaither. 1970. The effect of temperature on the reactivity of guinea pig complement with IgG and IgM hemolytic antibodies. Immunology. 19:967-981.

21. Gaither, T. A., I. Vargas, S. Inada, and M. M. Frank. 1987. The complement fragment $\mathrm{C} 3 \mathrm{~d}$ facilitates phagocytosis by monocytes. Immunology. 62:405-411.

22. Boyum, A. 1968. Isolation of mononuclear cells and granulocytes from human blood. J. Clin. Lab. Invest. 21(Suppl.):77-89.

23. Dorn, A. R., C. S. Moriarity, J. P. Osborne, et al. 1986. A new system for mononuclear cell separation. American Clinical Products Review. December.

24. Webster, R. O., and P. M. Henson. 1978. Rapid measurement of neutrophil exocytosis. Inflammation. 3(2):129-135.

25. Solomkin, J. S., L. A. Cotter, J. K. Brodt, and J. M. Hurst. 1985. Regulation of neutrophil superoxide production in sepsis. Arch. Surg. 120:93-98.

26. Bonferroni, A. 1957. An introduction to probability theory and its application. W. Felle, editor. 3rd ed. 110.

27. Bartholomew, D. J. 1959. A test of homogeneity for ordered alternatives. Biometrika. 46:36-48.

28. Stendahl, D., I. B. Coble, C. Dahlgren, and L. Molin. 1984. Myeloperoxidase modulates the phagocytic activity of polymorphonuclear neutrophil leukocytes. Studies with cells from a myeloperoxidase-deficient patient. J. Clin. Invest. 73:366-373.

29. Wilson, E., S. M. Costa, L. R. Gooding, and J. D. Lambeth. 1987. Platelet-derived growth factor stimulates phagocytosis and blocks agonist-induced activation of the neutrophil oxidative burst. A possible cellular mechanism to protect against oxygen radical damage. Proc. Natl. Acad. Sci. USA. 84:2213-2217.

30. Anderson, V., C. Kock, R. Vejlsgaard, and K. Wilken-Jensen. 1986. Fatal granulomatous disease. Acta Paediatr. Scand. 57:110-114.

31. Quie, P. G., J. D. White, B. Holmes, and R. A. Good. 1967. In vitro bactericidal capacity of human PMNs. Diminished activity of chronic granulomatous disease in childhood. J. Clin. Invest. 46:668679.

32. Bradley, P. P., R. D. Christensen, and G. Rouhstein. 1982. Cellular and extracellular myeloperoxidase in pyogenic inflammation. Blood. 60(3):618-622.

33. Bass, D. A., P. Olbrantz, P. Szedda, M. Seeds, and C. E. McCall. 1986. Subpopulations of neutrophils with increased oxidative product formation in blood of patients with infection. J. Immunol. 136:(3)860-866. 